\title{
Currículo em educação especial: tendências e debates
}

\author{
Laura Ceretta Moreira* \\ Roseli C. Rocha de C. Baumel***
}

\begin{abstract}
RESUMO
O texto discute o currículo em educação especial e como ambos os temas vêm recebendo atualmente atenção tanto das reformas educacionais quanto das pesquisas e da comunidade escolar, mesmo que com distintas formas de preocupação. Aponta-se para as tendências curriculares no ensino especial que, historicamente, se caracterizaram por propostas segregatórias que legitimaram currículos inadequados e alienantes, que, muitas vezes, contribuíram para infantilizar o aluno considerado deficiente. Apresentase considerações sobre as vertentes atuais de currículo em educação especial no Brasil, sobretudo as referentes às adaptações curriculares.

Palavras-chave: currículo, educação especial, necessidades educacionais especiais.
\end{abstract}

\begin{abstract}
The text discusses curriculum in special education and how much both themes are receiving attention now as much of educational reforms, research and school community, even if, with different concern forms. Its aiming curricula tendencies in special teaching that, historically, were characterized by segregate proposals, that legitimated inadequate and alienating curricula, this many times contributed to childish the student considered deficient. Is presented considerations about the curriculum's current tendencies in Brazilian special education above all, the referring to curricula adaptations.

Key-words: curriculum, special education, special educational needs.

* Professora do Setor de Educação da Universidade Federal do Paraná. Doutoranda do Programa de Pós-Graduação da Universidade de São Paulo. laura.moreira@uol.com.br

**Professora da Faculdade de Educação da Universidade de São Paulo. rbaumel@usp.br
\end{abstract}




\section{Educação especial e currículo: identificando concepções, represen- tações e movimentos}

Temas como educação especial e currículo vêm atualmente recebendo atenção das reformas educacionais, dos pesquisadores e da comunidade escolar, embora com distintas formas de preocupação. De um lado encontramos a tese da escola inclusiva, como aquela capaz de trabalhar com a diversidade e especializada em todas as crianças. De outro, o currículo entra em evidência, como uma questão que passa a ser estudada e debatida de forma intensa e diversificada tanto em âmbito internacional quanto nacional.

No presente artigo pretendemos abordar elementos que contribuam para uma reflexão do currículo em educação especial, nas concepções segregacionistas e nas integracionistas/inclusivistas. Lembramos que, com referência ao currículo em educação especial, dispomos ainda de tímidas iniciativas. $\mathrm{Na}$ obra Pesquisa em educação especial na pósgraduação, ${ }^{1}$ organizado por NUNES et al. (1998), percebemos que a produção científica em educação especial aumentou significativamente a partir do final da década de 70. Com efeito, das 149 dissertações de mestrado avaliadas pelos autores, 35 delas, ou seja, $23 \%$, versaram sobre o tema ensino-aprendizagem, que foi abordado a partir de diversos subtemas. Há uma tendência, nesses estudos, de propor, avaliar ou comparar a eficácia de programas de treinamento ou de práticas educativas interessadas na aquisição ou extinção de comportamentos/habilidades específicas dos alunos com necessidades especiais, demonstrando por parte dos pesquisadores interesses mais imediatos e pragmáticos. NUNES et al. (1998) dizem que os resultados dessas pesquisas sugerem:

[...] o desenvolvimento de pesquisas complementares, o aprofundamento das questões levantadas, a expansão de referenciais teóricos para a

1 O estudo retrata a análise crítica das dissertações em educação especial defendidas nos Programas da UFSCar e UERJ, de 1981 até 1995, que correspondem a uma estimativa de quase $60 \%$ de toda a produção científica discente sobre educação especial dos programas de pós-graduação do país. O conjunto de dissertações foi agrupado em sete núcleos temáticos, representando os temas mais freqüentes desses trabalhos, que são: Identificação e Caracterização, Ensino e Aprendizagem, Formação de Recursos Humanos, Atitudes e Percepções de Pais e Profissionais, Autopercepção, Profissionalização e Integração. 
elucidação de novas questões, a verificação dos fundamentos teóricos de propostas educacionais para alunos com necessidades especiais, a divulgação dos efeitos produzidos pelos programas e/ou procedimentos estudados, a utilização desses em atividades curriculares em salas de aula e a inserção dos conhecimentos produzidos no currículo de cursos em formação em educação especial. (NUENS et al., 1998, p. 52)

Vale destacar que o trabalho realizado pelos autores acima, aliado ao nosso acompanhamento na produção científica na área de currículo em educação especial, nos leva a afirmar o quanto a postura, inicialmente clínica e posteriormente psicoeducacional, negligenciaram análises mais críticas diante dessa temática. Essa parece ser uma lacuna que, só recentemente e de forma ainda tímida, começa a ser contemplada.

Nesse âmbito, consideramos importante levar em conta como a pessoa com necessidades especiais foi representada historicamente e como sua educação foi se constituindo, sobretudo no Brasil, pois a categoria do desvio, do atípico e do improdutivo, contribuíram para práticas segregativas, que legitimaram currículos inadequados e alienantes, que muitas vezes serviram mais para infantilizar o aluno considerado deficiente do que para garantir o direito às diferenças.

Em muitos aspectos, a concepção de deficiência reflete a maturidade humana e cultural de uma sociedade, FONSECA (1995) diz que há uma relatividade cultural que é tênue, sutil e obscura no processo de julgamento entre o deficiente e o não-deficiente, que de uma forma ou de outra procura afastar e excluir os indesejáveis, cuja presença pode perturbar ou ameaçar a ordem social.

Historicamente, deficiência e diferença foram concebidas como sinônimos, fazendo com que não se distinguisse limitações próprias da deficiência de limitações construídas socialmente. Assim, as pessoas com necessidades especiais foram consideradas naturalmente incapacitadas e passaram a fazer parte das chamadas minorias sociais, que, estigmatizadas, são segregadas, tal como os índios, os negros, as mulheres, as classes populares...

A educação especial foi fortemente influenciada pela idéia que as deficiências ou excepcionalidades são condições preestabelecidas, intrínsecas à individualidade e sem uma história social. Portanto, era preciso "normalizar a anormalidade." (FERREIRA, 1995, p. 14)

No Brasil, as primeiras iniciativas datam do período imperial e trazem historicamente as marcas da descontinuidade, da filantropia e do assistencialismo. 
É mais especificamente a partir da década de 60 que, timidamente, o poder público aponta ações à educação especial. FERREIRA $(1998$, p. 7) diz que:

Nas leis 4.024/61 e 5.692/71 não se dava muita importância para essa modalidade educacional: em 1961, destaca-se o descompromisso com o ensino público, já em 1971 o texto apenas indicava um tratamento especial a ser regulamentado pelos Conselhos de Educação - processo que se estendeu ao longo daquela década. É certo que o registro legal, por si, não assegura direitos, especialmente numa realidade em que a educação especial tem reduzida expressão política no contexto da educação geral, reproduzindo, talvez, a pequena importância que se concebe às pessoas com necessidades especiais - ao menos àquelas denominadas deficientes em nossas políticas sociais.

É, principalmente, a partir dos últimos dez anos que a educação especial brasileira reflete um certo crescimento em relação à educação geral. Hoje temos um considerável número de dispositivos legais na forma de Leis, Decretos, Portarias, Resoluções, Instruções e Medidas Provisórias no âmbito da Legislação Federal, Estadual e Municipal, que por si só não alteram a realidade social, mas que são um avanço na área jurídica e na busca de direitos que foram negados.

Exemplo disso é a própria LDB 9.394/96, que, no Capítulo V, afirma, em seu artigo 58, que a educação dos portadores de necessidades especiais se deve dar, preferencialmente, na rede regular de ensino. Esta questão tem gerado muita polêmica na comunidade em geral, principalmente na escolar, pois se, de um lado, a busca por uma educação de qualidade para todos é uma luta histórica, por outro, as ações governamentais sustentadas em práticas neoliberais, que apontam para a organização autônoma da população e para a formação de associações privadas, entendendo ser este o caminho para uma "sociedade igualitária", têm causado incertezas e inquietações em relação à atuação do Estado na garantia e no cumprimento de suas obrigações para a efetivação de uma educação que respeite a diversidade.

O movimento pela educação inclusiva se intensifica a partir da Conferência Mundial de Jointiem, Tailândia, realizada em 1990, que apontou para a Educação para Todos, e é retomada na Conferência Mundial sobre Necessidades Educativas Especiais, ocorrida na Espanha, em 1994, que culmina na Declaração de Salamanca. Movimentos que, indiscutivelmente, configuram 
um avanço nos direitos dessas pessoas, mas que também devem ser analisados frente à sintonia existente entre os organismos internacionais e os governos.

Particularmente, os compromissos globais para a educação, através de eventos internacionais, têm se intensificado a partir da década de 1980, bem como a alocação de recursos para o desenvolvimento do que é proposto nos projetos firmados nos eventos, que se dão por meio de agências internacionais, de modo particular o Banco Mundial. Nesse cenário de "globalização das agendas educacionais", ${ }_{2}^{2}$ merece especial atenção o contexto educacional brasileiro.

\section{Currículo em educação especial: dos programas segregatórios às propostas de inclusivistas}

\section{Da concepção clínica à psicoeducacional}

A educação especial foi constituída por ações ligadas à assistência, filantropia e reabilitação. Isso, logicamente, refletiu na formação e capacitação de seus recursos humanos, na organização de seus serviços e atendimentos e na concepção de seus currículos. Lembrando que o currículo está relacionado às seleções feitas no interior da cultura e seu processo de organização é o modo no qual as prioridades são decididas e postas em prática (FORQUIN, 1993)

O pensamento de TELFORD e SAWREY (1984), expresso na obra $O$ indivíduo excepcional, muito referendado no Brasil na década de 70 e 80 , dizia que "ser excepcional é ser raro e incomum. O incomum, o bizarro e o inesperado sempre atraíram a atenção e freqüentemente despertaram medo e espanto." (TELFORD; SAWREY, 1984, p. 15) Da mesma forma apontava que os programas de instrução individualizada automatizados eram utilizados com sucesso em inúmeros sistemas escolares, de diversos países, demons-

2 Termo utilizado por VEIRA, S. L. Políticas internacionais e educação-cooperação ou intervenção. In: REUNIÃO ANUAL DA ANPED, 22., 1999, Caxambu. Anais... Caxambu: [s.n.], 1999. 
trando que os programas de diagnóstico-prescritivo para crianças excepcionais continuavam a ser "uma profissão de fé entre a maioria dos educadores especializados." (TELFORD; SAWREY, 1984, p. 161)

Permanece até meados de 1970 a influência da Psicologia e das Ciências da Saúde. Dessa forma, a formação de professores para atuar em educação especial distancia-se dos ideais pedagógicos de compromisso político-social e são um espaço eminentemente clínico, de ortopedia mental. É comum terminologias como "prognóstico", "diagnóstico", "terapia" e a busca de refinadas técnicas de avaliação para detectar possíveis patologias.

MAZZOTTA (1993) lembra que o professor de educação especial não deve se distanciar do pedagógico. Entretanto, tradicionalmente, tanto o trabalho do professor de ensino especial, como as propostas curriculares para a educação especial, guiaram-se pela concepção do ajustamento social, no qual corrigir precedia o educar. Portanto, currículos por desempenho, com modelagem detalhada de respostas e condutas, foram largamente utilizados de forma abstrata e descontextualizados da própria realidade do aluno.

Um dos marcos históricos para se compreender a produção de um currículo oficial em educação especial é o trabalho do Centro Nacional de Educação Especial - Cenesp, existente de 1973 a $1986 .{ }^{3}$ Esse centro apresentou a situação da educação especial no Brasil demonstrando que uma pequena parcela dos deficientes recebia alguma forma de atendimento. Da mesma forma organizou um cadastro geral dos estabelecimentos do ensino especial e elaborou um plano de ação para o período de 1975/1979, elegendo como áreas prioritárias a capacitação de recursos humanos, a reformulação de currículos ${ }^{4}$ e assistência técnica e financeira aos sistemas estaduais e às instituições privadas de educação especial ${ }^{5}$. Iniciou-se, assim, a elaboração de propostas curriculares para as áreas de deficiência mental, auditiva, visual e para superdotados.

3 Este órgão foi substituído em 1986 pela Secretaria de Educação Especial - Sespe, basicamente com as mesmas competências do Cenesp. Em 1990, com a reestruturação do Ministério de Educação, foi extinta a Sespe e as atribuições relativas à educação especial passaram para a Secretaria Nacional de Educação Básica - Seneb. Com a queda de Collor em fins de 1992, ocorreu nova reorganização dos ministérios e surgiu novamente a Secretaria de Educação Especial - Seesp - ligada ao MEC e existente até hoje.

4 As propostas curriculares para deficiência auditiva foram elaboradas pela Pontifícia Universidade de São Paulo - PUC-SP, as propostas para deficientes mentais e visuais foram organizadas pela Universidade do Estado do Rio de Janeiro - UERJ, e de superdotados pela Universidade Federal de Minas Gerais, caracterizando um processo no qual planejadores competentes organizam propostas para serem executadas pelo professor da educação especial.

5 Cumpre salientar que essas ações do Cenesp merecem destaque, pois até então a educação especial brasileira não dispunha de nenhum tipo de mapeamento ou planejamento desse porte. 
O plano de educação especial de 1977/79 evidencia que a revisão e as adaptações curriculares deveriam ser pautadas na "elaboração de propostas curriculares e respectivos manuais de orientação para o ensino de excepcionais de $1^{\circ} \mathrm{Grau}$, na forma de modelo de currículos por desempenho, sob o enfoque sistêmico." (BRASIL, 1977, p. 24-25).

Assim, as propostas curriculares que foram organizadas durante o período de existência do Cenesp e que influenciaram as décadas de 70 e 80 deixam bem evidente a forte influência da psicologia comportamental e do enfoque sistêmico. Organizam-se currículos fechados, segregatórios e especialmente técnicos, aos moldes de TYLER (1974), ${ }^{6}$ TURRA (1976) e TRALDI (1977).

Para GOODSON (1997), o currículo formal na sua expressão oficial ou o currículo escrito constitui-se em um testemunho, uma fonte documental, um dos melhores guias oficiais sobre a estrutura institucionalizada da escolarização, mas quando restrita ao rol de matérias e aos programas com análise isolada, torna-se insuficiente e passível de distorções.

Lembramos que se, de um lado, é preciso que o currículo expresse e articule as diferenças, no sentido de respeitá-las, é também preciso "compreender como as relações nas quais as diferenças são construídas operam como parte de um conjunto de práticas sociais, políticas e culturais." (GIROUX, 1993, p. 53) Se educação especial é, antes de tudo, "educação", portanto, identifica-se perfeitamente com seus condicionantes, seus pressupostos, seus objetivos e finalidades. "O desafio é que o 'especial' não se distancie da 'educação'.” (FERREIRA, 1995, p. 85)

\section{As vertentes atuais do currículo na educação especial}

A Política Nacional de Educação Especial, do MEC, define que as classes especiais integradas à escola comum devem adotar "o currículo regular oficial, com as devidas adaptações e o processo de ensino-aprendizagem deverá ser baseado em avaliação/diagnóstico de natureza educacional." (BRA-

6 TYLER, R. W. Princípios básicos de currículo em ensino. Porto Alegre: Globo, 1974. A primeira edição dessa obra foi lançada no Brasil em 1974, entretanto seu pensamento já vinha influenciando vários autores brasileiros no campo do currículo. 
SIL, 1994, p. 38) Alerta para a importância de um "atendimento educacional adequado às necessidades especiais do alunado, no que se refere a currículos adaptados, métodos, técnicas e material de ensino diferenciado, ambiente emocional e social da escola favorável à integração social dos alunos, pessoal devidamente qualificado.” (BRASIL, 1994, p. 51)

Para discutirmos questões atuais da educação especial e o currículo neste contexto, convém elucidarmos como a mesma tem sido definida oficialmente e quem são os alunos considerados com necessidades educacionais especiais.

De acordo com a Política Nacional de Educação Especial e a LDB 9.394/ 96, a educação especial é uma modalidade educacional que se constitui através de um conjunto de recursos e serviços educacionais especiais, organizados para apoiar, complementar, suplementar e, em alguns casos, substituir os serviços educacionais comuns, de modo a garantir a educação formal aos alunos que apresentam necessidades educacionais. Assim, requer uma prática formativa na qual os recursos e os programas pedagógicos correspondam às especificidades dos alunos que apresentam altas habilidades/superdotação, deficiência auditiva, visual, física/motora e múltiplas e condutas típicas de síndromes, quadros psicológicos, neurológicos ou psiquiátricos.

Apesar de não ser propósito deste artigo realizar uma análise da LDB 9.394/96 frente à educação especial, já bem discutida por inúmeros especialistas brasileiros ligados a esta área, alguns desdobramentos da lei, como por exemplo o artigo $59 \mathrm{em}$ seu inciso I, que respalda as adaptações curriculares, merecem destaque para que possamos melhor avaliar as conseqüências das reformas educacionais brasileiras, que proclamam uma escola que atenda à diversidade, inspirada num modelo curricular que recebeu forte influência do pensamento de Cesar Coll, mentor da reforma espanhola e consultor no Brasil para a construção dos Parâmetros Curriculares Nacionais (PCNs).

Neste momento, iremos nos reportar para alguns aspectos do documento: "Adaptações curriculares dos PCNs para a educação de alunos com necessidades especiais", produzido em 1999 conjuntamente com as Secretarias de Educação Fundamental e Educação Especial, que baseia-se no pressuposto de que a realização de adaptações curriculares visa atender às necessidades particulares de aprendizagem dos alunos. Bem como implicam em planificações pedagógicas e ações docentes fundamentadas em critérios que definem: "o que o aluno deve aprender, como e quando aprender, que formas de organização de ensino são mais eficientes para o processo de aprendizagem, como e quando avaliar o aluno." (MEC, 1999, p. 33)

Esses critérios nos fazem lembrar o modelo de currículo proposto por TYLER (1974) através da obra Princípios básicos de currículo e ensino, já 
mencionado anteriormente como um dos grandes representantes das teorias tradicionais do currículo, o autor centra suas idéias nas questões de organização, desenvolvimento e técnicas do currículo.

Uma análise do currículo, segundo Cesar Coll, feita por MOREIRA (1997), elucida pontos de suma importância que servem também para compreender a perspectiva da escola inclusiva diante do ajustamento de seu currículo à diversidade, mais no ângulo das características individuais do que das diferenças culturais. Da mesma forma, encontramos similaridades existentes no modelo de currículo proposto por TYLER (1974), que se atem às seguintes questões: que objetivos educacionais a escola deve procurar alcançar? Como selecionar experiências de aprendizagem que possam ser úteis na consecução desses objetivos? Como podem ser organizadas as experiências de aprendizagem para um ensino mais eficaz? Como se pode avaliar a eficácia das experiências de aprendizagem?

Segundo MOREIRA (1997, p. 103), essas questões são importantes, porém enquanto:

Tyler discute o que fazer para então voltar-se para o como fazer, Coll secundariza a discussão do que fazer, transforma a psicologia em fonte e a utiliza como subsídio básico das longas considerações referentes ao quando e como ensinar e a o que, quando e como avaliar. O que confere à discussão um lastimável caráter burocrático.

Existe o perigo de novamente haver uma preocupação do como fazer através de uma pedagogia psicológica, que torna o currículo técnico, simplista e com feições de liberdade, sobretudo porque o professor pode realizar adaptações e selecionar conteúdos significativos ao aluno com necessidades educacionais especiais.

Segundo o MEC (1999), as adaptações curriculares são medidas pedagógicas que devem ser adotadas em diversos âmbitos, tais como: no projeto pedagógico da escola, na sala de aula, nas atividades em geral e, somente quando absolutamente necessário, devem aplicar-se ao aluno individualmente.

Com relação às adaptações curriculares para o aluno com necessidades educacionais especiais devemos lembrar, de um lado, MOREIRA (1997), ao enfatizar que o projeto pedagógico da escola não pode se traduzir simplesmente em princípios e normas de ações úteis e eficazes, denotando um cará- 
ter eminentemente prescritivo para definir a prática. E de outro, a forma como vem sendo incluído o "aluno especial" no ensino regular, com escolas que, em sua grande maioria, não atendem suas necessidades básicas e com professores que não receberam ao longo de sua formação, inicial ou continuada, subsídios concretos acerca desses alunos. Indagamos, então, em que condições serão realizadas as adaptações curriculares?

É importante salientarmos que, após a promulgação da nova LDB, começou a ocorrer em todo Brasil a desativação de classes especiais, muitas vezes, sem a contrapartida da criação de outros apoios especializados indicados na legislação. Sabemos que uma das principais barreiras para se efetivar a inclusão é o despreparo do professor para receber, em suas salas de aula superlotadas, não só o aluno com deficiência visual, auditiva, motora ou mental, mas todos aqueles que não se enquadram dentro do padrão imaginário do aluno "normal". Esse aluno "diferente" ainda é, para o professor, abstrato e desconhecido. Infelizmente, a grande maioria dos currículos dos cursos de formação continua privilegiando o aluno idealizado e o mito das classes homogêneas.

Consideramos, portanto, bastante temeroso esperar que os professores do ensino regular, solitariamente, realizem adaptações curriculares para o (os) aluno (os) com necessidades educacionais especiais inserido (s) na classe comum.

As adaptações curriculares não podem correr o risco de produzirem na mesma sala de aula um currículo de segunda categoria, que possa denotar a simplificação ou descontextualização do conhecimento. Com isso, não queremos dizer que o aluno incluído não necessite de adaptações curriculares, de apoios e complementos pedagógicos, de metodologias e tecnologias de ensino diversificadas e que as escolas especiais não organizem propostas curriculares articuladas ao sistema público de ensino. Estamos argumentando em favor de uma inclusão real, que repense o currículo escolar, que efetive um atendimento público de qualidade. Para TORRES SANTOMÉ (1996), existe a necessidade de um planejamento curricular calcado na análise das situações sociais e educativas e de seus problemas mais urgentes para que o enfrentamento da situação ocorra. 


\section{Considerações finais}

Apesar de o currículo ter uma história recente e a educação especial apenas no final do século XX ser considerada uma modalidade escolar, ambos estão no centro das discussões atuais. Temos, tanto das teorias críticas como pós-críticas do currículo, aprendizados importantes que tornam impróprio pensarmos o currículo, pela via reduzida das grades curriculares, listagem de conteúdo, apenas como um aparato neutro e técnico.

Para APPLE (1994), toda a sociedade marcada por uma distribuição desigual de poder necessita reconhecer abertamente diferenças e desigualdades, pois é a partir do reconhecimento das diferenças que o diálogo do currículo pode prosseguir.

Sabemos que as vozes das pessoas com necessidades especiais foram silenciadas de praticamente todos os movimentos, conseqüentemente o currículo destinado a elas foi descontextualizado e segregatório. Entendemos que o aluno com necessidades educacionais especiais somente irá se beneficiar da proposta inclusiva se as diferenças não forem eliminadas, mas respeitadas.

É incontestável que o professor deve possuir um papel participativo e criativo na elaboração e no desenvolvimento de novos currículos e de adaptações curriculares, sobretudo para os alunos com necessidades educacionais especiais. Com nos lembra SACRISTÁN (1998), é imprescindível que ocorra o enfoque coletivo da profissionalização docente para que se desenvolva um currículo para os alunos. Visto que "o isolamento nas salas supõe a falta de questionamento das estruturas e decisões que dependem de instâncias coletivas." (SACRISTÁN, 1998, p. 98)

Assim, é preciso que a escola, os professores e a família tenham uma rede de apoio. Será muito difícil, por exemplo, para o professor, articular adaptações curriculares com salas de aula superlotadas, sem o apoio de uma equipe interdisciplinar ou da equipe técnico-pedagógica da escola, sem receber das instituições formadoras subsídios concretos, sem uma qualificação em serviços de qualidade, sem dispor dos apoios e complementos para o seu aluno com necessidades especiais. Não somos contrárias ao movimento de inclusão, tampouco às adaptações curriculares, ao contrário, sabemos que elas são importantíssimas aos alunos. Entretanto, a forma como as políticas públicas têm encaminhado na prática essas questões evidenciam a secundarização de aspectos imprescindíveis não só aos alunos com necessidades educacionais especiais, mas a todos os alunos, sobretudo àqueles ligados ao sistema público de ensino. 


\section{REFERÊNCIAS}

APPLE, M. A política do conhecimento oficial: faz sentido a idéia de um currículo nacional. In: MOREIRA, A. F.; SILVA, T. T. (Org.). Currículo, cultura e sociedade. São Paulo: Cortez, 1994.

BRASIL. Lei n. 9394/96 de 20 de dezembro de 1996. Lei de Diretrizes e Bases da Educação Nacional (LDB). Diário Oficial da República Federativa do Brasil, Brasília, n. 248, 23 dez. 1996.

BRASIL. MEC. Diretrizes básicas para a ação do Centro Nacional de Educação Especial. Rio de Janeiro: CENESP, 1974.

. Plano Nacional de Educação Especial 1977/1979. Brasília: CENESP, 1977.

BRASIL. MEC. Política Nacional de Educação Especial. Brasília: SEESP, 1994.

BRASIL. MEC. Parâmetros Curriculares Nacionais. Brasília: Secretaria de Educação Fundamental, 1997.

BRASIL. MAS. CORDE. Declaração de Salamanca e linha de ação sobre necessidades educativas especiais. Brasília, 1994.

FERREIRA, J. R. A exclusão da diferença: a educação do portador de deficiência. Piracicaba: Unimep, 1995.

A nova LDB e as necessidades educativas especiais. Caderno CEDES, São Paulo, n. 46, 1998.

FONSECA, V. da Educação especial: programa de estimulação precoce uma introdução das idéias de Feuerstein. Porto Alegre: Artes Médicas, 1995.

FORQUIN, J. Escola e cultura: as bases sociais e epistemológicas do conhecimento escolar. Porto Alegre: Artes Médicas, 1993.

GIROUX, H. O pós-modernismo e o discurso da crítica educacional. In: SILVA, T. T. Teoria educacional crítica em tempos pós-modernos. Porto Alegre: Artes Médicas, 1993.

GOODSON, I. A construção social do currículo. Lisboa: EDUCA, 1997.

MAZZOTTA, M. J. S. O trabalho docente e a formação de professores de educação especial. São Paulo: EPU, 1993. 
MEC. SEESP. Parâmetros Curriculares: adaptações curriculares - estratégias para a educação de alunos com necessidades educacionais especiais. Brasília: Secretaria de Educação Fundamental, 1999.

MOREIRA, A. F. A psicologia...e o resto. Caderno de Pesquisa, São Paulo, n.100, p. 93-107, mar. 1997.

. Currículo: questões atuais. São Paulo: Papirus, 1997.

NUNES, L. R. P. et al. Pesquisa em educação especial na pós-graduação. Rio de Janeiro: Sette-letras, 1998.

SACRISTÁN, G. O currículo: uma reflexão sobre a prática. Porto Alegre: Artes Médicas, 1998.

TELFORD , C.; SAWREY, J. O indivíduo excepcional. Rio de Janeiro: Zahar, 1974.

TORRES, S. A reforma educativa e a psicologização dos problemas sociais. Educação e Realidade, Porto Alegre, v. 21, p. 23-45, 1996.

TRALDI, L. L. Currículo: conceituações e implicações. São Paulo: Atlas, 1977.

TURRA, C. et al. Planejamento de ensino e avaliação. 3. ed. Porto Alegre: Meridional EMMA, 1976.

TYLER, R. W. Princípios básicos de currículo e ensino. Porto Alegre: Globo, 1974. 